\title{
B.
}

\section{Recruitment and training of prison doctors}

\author{
Will remain difficult while Britain's prisons are so dispiriting
}

The disgraceful state of our prisons has been highlighted yet again by the series of riots that started earlier this year at Strangeways ${ }^{1}$ and by the independent reports of the Chief Inspector of Prisons, Judge Stephen Tumim, the most recent of which was published last week (p 253). These reports have graphically described the overcrowding, the squalid conditions, the minimal provision for occupation and recreation, and the failure to rehabilitate prisoners while they are so expensively captive-factors that might have prompted the committee of the European convention on degrading treatment or punishment to make its first visit of inspection to Britain ( $p$ 253). This unsatisfactory working environment inevitably affects recruitment of staff of all kinds and the quality of the services.

The Prison Medical Service has long been a cause for concern and the subject of periodic reports. ${ }^{2}$ Yet another, the "internal scrutiny" ordered by the then Minister of State, $\mathrm{Mr}$ David Mellor, has recently been completed but not yet published. In 1985-6 the House of Commons Social Services Committee carried out a wide ranging inquiry into the Prison Medical Service ${ }^{3}$ that led to the Royal College of Physicians establishing a working party to consider the recruitment and training of prison medical officers. It reported in March 1989, but its report has only just been published. ${ }^{+}$The working party briefly considered the option of bringing the service into the NHS, only to dismiss it as impracticable (although the report was compiled before the provider-purchaser model of the new NHS was known). The notion of a special health authority was also summarily dismissed.

Prisoners generally come from deprived backgrounds and have a high prevalence of physical and mental disorders: their symptoms are often exacerbated by the poor environment; and the prevailing doctor-patient relationship is unsatisfactory. Prison doctors are responsible for the general medical care of inmates and have to perform an enormous number of routine examinations. Psychiatric care constitutes much of their work, together with court reports, fitness for punishment assessments, and the provision of general advice on health care and hygiene. There are currently five principal medical officers, 34 senior medical officers, and 76 full time and 126 part time medical officers. Recruitment is difficult, and the calibre and experience of many applicants are unsuitable. Although rudimentary training opportunities exist, "it is difficult to make the arrangements," and officers gain experience by working with a more senior colleague.

The working party recognises a specialty of prison medicine and proposes a joint accreditation board to approve training posts for junior medical officers. Trainers would be approved from among senior doctors. Junior medical officers would undertake three years' training: two years in a prison and one working in a discipline in which their experience is deficient. Entrants would be general practitioners with an MRCGP and hospital trained doctors with a higher diploma. Pay would be comparable with that of senior registrars, and the work programme would be similar, including training appropriate to the needs of the Prison Medical Service, sessions outside, and eventual accreditation, leading to appointment in competition to a career post. Career progression would entail increasing responsibility and a requirement to work outside the prison, maintain professional contacts, and undertake continued postgraduate education. The royal colleges together with the Department of Health and the Prison Medical Service are now to consider a diploma in prison medicine for those who complete training successfully.

These proposals should be welcomed; an improvement in the quality and status of prison doctors is long overdue. But without improvements in working conditions, the training of prison nursing staff, and the interlocking of the Prison Medical Service with services for offenders outside prison, how will a career in prison medicine compete with the attractions of alternatives elsewhere? Will an accreditation board find enough qualified trainers? These are serious questions. The reservations on these recommendations expressed in the report's appendix by John Kilgour, then director of the Prison Medical Service and a member of the working party, give little cause for encouragement.

A radical and urgent change in the organisation and resources of the Prison Medical Service is essential to underpin these highly desirable recommendations on education and training, and it is to be hoped that improvements will result from the Home Office "scrutiny." But if the quality of care is to be substantially raised the Home Office must also improve conditions for all prisoners, reduce overcrowding, use prisoners' time in custody usefully, and ensure decent prison hospitals integrated with outside services. Without a fundamental change in the system a few well trained doctors 
will continue to struggle to care for their patients in the face of a degree of adversity that will tend to defeat them.

ROBERT BLUGLASS

Professor of Forensic Psychiatry,

University of Birmingham,

Reaside Clinic,

Birmingham B18 5SD

1 Delamothe T. Strangewavs. Br.Med 7 1990:300.967

Bluglass R. Mentally disordered prisoners: reports but no improvements. Br Med f 1988;296 $1757-8$.

3 House of Commons Social Services Committee. Third report from the social services committee session 1985-86: prison medical service. I. Report. 2. Minutes of evidence. London: HMSO, 1986.

4 Working Party of the Royal College of Physicians. Report to the chief medical officer, March 1989. The prison medical service in England and Wales: recruitment and training of doctors. London: Home Office and Department of Health, 1990.

\section{Liver function tests}

\section{With all their imperfections the standard tests are still widely used}

The liver's functions include carbohydrate, lipid, and protein metabolism; the production of bile acids; the detoxification and excretion of lipid soluble compounds; and storage. All these functions may be investigated - though few are tested in clinical practice. ${ }^{1}$ Most clinical biochemistry laboratories offer packages of liver function tests that include measurement of serum bilirubin concentrations and alkaline phosphatase and aminotransferase activities. Serum albumin concentrations will often be included, and further discretionary tests such as measurement of $\gamma$-glutamyltranspeptidase activity and direct serum bilirubin concentrations and urine analysis are usually available.

Strictly speaking, the term liver function test is inaccurate as enzyme activities reflect dysfunction and are not specific to the liver, while bilirubin and protein concentrations are affected by factors such as haemolysis and nutritional state. The results of other biochemical tests-for example, measurement of plasma ammonia and $\alpha$-fetoprotein concentrations - may sometimes be of value, though they are not tests of general liver function. More elaborate investigational techniques have been introduced, including endoscopic cholangiography, ultrasonography, and computed tomography. With the availability of these and of liver biopsy, measurement of clotting factors, immunological investigations, and investigation of markers of hepatitis, are some liver function tests outmoded? Should newer dynamic tests that come closer to assessing specific hepatic functions replace the standard tests?

Liver function tests are used to identify patients with liver disease; in the differential diagnosis of jaundice; to monitor the severity, course, and response to treatment of disease; and to detect hepatotoxicity caused by drugs. The sensitivity (positive results in patients with disease ${ }^{2}$ ) of liver function tests has been found to be $59-90 \%$, depending on the histological abnormality, when liver biopsy and biochemical investigations have been studied. ${ }^{34}$ Specificity (negative results in patients free of disease) is not a useful concept in this setting as the reference ranges for the tests are based on $95 \%$ confidence intervals and $2 \cdot 5 \%$ of healthy people will have an abnormality of each test. Serum enzyme activities are also increased in other disease states-for example, alkaline phosphatase in bone disease and aspartate aminotransferase after myocardial infarction. The specificity of the tests may be improved by measuring more hepatospecific enzymes such as alanine aminotransferase, using additional tests such as isoenzyme determinations, and interpreting investigations in the light of clinical history and physical examination. The standard technique for establishing whether liver disease is present is histological examination of a liver biopsy specimen, though even this is not perfect as sampling errors may occur ${ }^{5}$ and interpretation may vary. ${ }^{6}$ Ethical considerations preclude an accurate assessment of specificity in unselected people. The frequency of abnormal results, however, may be calculated in selected groups in which liver biopsy specimens are normal. Thus Galambos and Wills found that the specificity of liver function tests was $11-74 \%$ for mild and $19-84 \%$ for more definite abnormalities. ${ }^{3}$ The predictive value of positive results (the percentage of positive results that are true positive results) varied from $56 \%$ to $88 \%$ when mildly abnormal, although a threefold rise in alanine aminotransferase activity had a predictive value of $95 \%$; the predictive value of negative results was $87-97 \% .{ }^{+}$Utility has been defined by Hofmann as the extent to which results cause a meaningful change in management. ${ }^{7}$ The results of liver function tests have a low utility in identifying patients with treatable disease $\left(18 \%^{4}\right)$, although this figure may change with therapeutic advances and it does not include negative management decisions such as avoiding particular drugs.

If conventional liver function tests are unsatisfactory what alternatives are there? Dynamic tests such as galactose clearance, and bromosulphthalein and indocyanine green excretion have been available for many years, but they are not widely used. Serum bile acid concentrations depend partly on intestinal function and seem to be less sensitive than originally suggested, even if measured two hours after meals. ${ }^{7}$ They may, however, be better than conventional tests in patients with chronic liver diseases such as cirrhosis ${ }^{8}$ and may be more useful in predicting the severity of histological abnormality in patients with chronic hepatitis. ${ }^{9}$ The ${ }^{13} \mathrm{C}$-aminopyrine demethylation breath test quantitatively assesses hepatic microsomal metabolism and has been found to be more specific $(84 \%)$ and equally sensitive $(86 \%)$ to measuring serum bile acid concentrations when differentiating patients with chronic active hepatitis with bridging or cirrhosis from those with mild chronic active or chronic persistent hepatitis. ${ }^{9}$ Caffeine excretion assessed by breath ${ }^{14} \mathrm{CO}_{2}$ excretion or by plasma clearance after injection of 3-methyl- ${ }^{14} \mathrm{C}$ caffeine, also is a measure of microsomal activity, and encouragingly accurate results have been reported in patients with cirrhosis. ${ }^{10}$ More data on these dynamic tests are needed, although the difficulties will remain that they require a greater investment of time than standard liver function tests and that the analytical methods are less straightforward. They may prove to be valuable research techniques. ${ }^{11}$

Alternative measurements in serum have been described, which show promise. Measurements of glutathione $S$ transferase seem to be more sensitive and organ specific than other enzymes in assessing of hepatocellular damage, ${ }^{12} 13$ and quantification of conjugated bilirubins may provide more specific information on hepatic bilirubin metabolism. ${ }^{14}$ Other investigations that may find wider application include measurement of desialylated transferrin concentration and mitochondrial aspartate aminotransferase activity in patients who abuse alcohol, ${ }^{15}{ }^{16}$ and procollagen III peptide and M2 autoantigen concentrations in patients with primary biliary cirrhosis. ${ }^{1718}$

The value of these tests must be confirmed and assay methods improved if they are to find general application. Until then, existing liver function tests-with all their 